\title{
A systematic review of media parenting in the context of childhood obesity research
}

\author{
Alyssa Aftosmes-Tobio ${ }^{*}$, Claudia Ganter ${ }^{1}$, Selma Gicevic ${ }^{1}$, Sami Newlan², Christine L. Simon², \\ Kirsten K. Davison ${ }^{1}$ and Jennifer A. Manganello ${ }^{4}$
}

\begin{abstract}
Background: We conducted a systematic review to obtain studies on childhood obesity and parenting published between 2009 and 2015, and draw out those studies with a particular focus on media parenting. Our analysis addresses two major aims: 1) to describe how media use and media-related parenting practices and skills are operationalized in studies and 2) to explore whether studies measured ecological factors (e.g. individual-, family-, and community-level factors), which could be associated with media parenting practices.
\end{abstract}

Methods: Using a standardized, multi-stage process, we identified and screened articles focused on parenting and childhood obesity $(N=667)$. Studies were eligible for this analysis if they measured media parenting and/or the home media environment, resulting in a sample of 103 studies. We used quantitative content analysis to code the full text articles for content related to our study aims; analyses were performed using SAS 9.4.

Results: Seventy nine percent of studies measured media use, $82 \%$ measured media parenting, and $65 \%$ measured the home media environment. Studies measuring media use focused on a limited number of devices; while all studies measured child/parent use of televisions, only $3 \%$ measured use of smartphones, $1 \%$ measured use of laptops, and no studies measured use of tablets. Measures of parenting practices focused largely on rules specific to limiting screen time. Although $60 \%$ of studies measured at least one ecological factor, child-specific and neighborhood/communitylevel factors were rarely measured.

Conclusions: More detailed measurements of media use that reflects current technology trends and diverse contexts of use are needed to better understand media use and parent regulation of child media exposure. Measures of the ecological context can more fully assess factors impacting media parenting and, subsequently, child risk for overweight and obesity.

Keywords: Childhood obesity, Media parenting, Home media environment, Systematic review

\section{Background}

The American Academy of Pediatrics (AAP) recommends children spend no more than 1 to $2 \mathrm{~h}$ per day using screens [1], yet, it has been documented that children spend more time using screen media than attending school [2]. Screen media includes televisions (TV), video gaming systems, computers, cell- or smartphones, and other electronic devices such as tablets or laptops $[3,4]$. According to a recent Kaiser Family Foundation report, children ages 8 to 10 years-old spend nearly $8 \mathrm{~h}$

\footnotetext{
* Correspondence: aaftosme@hsph.harvard.edu

'Department of Nutrition, Harvard T.H. Chan School of Public Health, 665

Huntington Avenue, Boston, MA 02121, USA

Full list of author information is available at the end of the article
}

using media each day, while teenagers spend more than $11 \mathrm{~h}$ [5]. While there is an evidence base on the harmful effects of TV viewing on children's risk of obesity [6-8], we know much less about the effect of modern screen based devices such as smartphones and tablets [9]. Rapidly evolving forms of media demand creativity and adaptability on the part of researchers looking to capture device use among children and make recommendations to parents on how to intervene on their child's use.

Parents shape child behaviors through modeling, guiding their children through reinforcement, and controlling their environments [10-14]. They play a significant role in monitoring child media consumption and helping them find alternative activities. Although studies have 
previously explored parenting practices associated with child exposure to specific types of media content, there has been limited research focused on the implications of media parenting practices for obesity prevention [3]. Jago, et al. recently published a systematic review [13] of 29 studies examining associations between media parenting and child screen viewing, with a particular focus on parenting measures. The authors reported inconsistent relationships between parenting and child screen use, and highlighted important shortcomings in parenting measures. This review did not focus on childhood obesity, nor did it provide a systematic and quantitative assessment of how child media use was operationalized.

As a result of the dramatic proliferation in child screen use, there is an increasing need for interventions to support parent modulation of child screen use. It is questionable, however, if the literature is at a stage of development to support the creation of such programs. Thus, at this time it is important to take stock of the available evidence. In particular, it is important to document the specific media devices and media parenting practices measured in studies, and the extent to which studies have examined the ecological context. This information is crucial to understand gaps in the literature that must be addressed. With this in mind, we conducted a systematic review to identify studies on childhood obesity and parenting, and draw out those studies with a particular focus on media parenting. By doing this, our analysis addresses two major aims: 1) to describe how media use and media-related parenting practices or skills are operationalized in studies; and 2) to explore whether studies included measures of ecological factors, which could be associated with media parenting.

\section{Methods}

For this study, a multi-stage process was used to: 1) identify articles on parenting in the context of childhood obesity; 2) screen for eligibility; and 3) compile a final sample of studies for full-text coding. Five databases (PubMed, EMBASE, Academic Search Premier, PsycINFO, and CINAHL) were searched to identify studies for inclusion. The final database search was conducted in December 2015 (see Fig. 1). We used search terms related to parents or parenting, and obesity or obesity-related risk behaviors (see Additional file 1 for an example of search terms used); included search terms related to media use, devices, and media parenting; and limited our search to parents/caregivers of children $0-18$ years of age. We also used terms to exclude unrelated topics unrelated, such as family history or pregnancy, as well as non-research studies (e.g., letters, reviews, commentaries). A total of 5557 unique studies were identified after removing 4499 duplicates. An initial screening of study titles eliminated those meeting the following exclusion criteria: focused on unrelated topics (e.g. food safety), were not written in English, included animals, targeted a clinical population (e.g. children with spina bifida), or were not original research (e.g. commentaries, letters), resulting in a pool of 2080 studies. Two coders then applied eligibility criteria to study abstracts. Eligible studies included non-intervention, peerreviewed research studies written in English that focused on parenting (e.g. measured parenting behaviors, styles, or cognitions), were relevant to childhood obesity (e.g. diet, sedentary behavior), included parents/caregivers as research participants, and were published between January 2009 and December 2015. This time parameter was chosen to capture the most recent literature available and for the feasibility of coding, given the high volume of studies identified in this seven-year time period alone. Intervention studies were excluded from the sample because they require a separate coding scheme, which was beyond the scope of the present study. Consistent with systematic review guidelines [15] only one article per study was included in the analysis. When multiple articles from the same study were identified, we included the first published article. When multiple articles from the same study were first published in the same month, we randomly selected one article to include in the sample.

The two coders achieved $90 \%$ agreement in applying the eligibility criteria, and all discrepancies were discussed and resolved. A total of 1170 studies did not meet the eligibility criteria or could not be located, resulting in a sample of 667 studies representative of recent literature on parenting and childhood obesity. A separate analysis was conducted on the total pool of eligible studies and is reported elsewhere [16]. Studies were eligible for the present analysis if they were coded as measuring media parenting practices (e.g., rules around TV/computer/video game or other media use) and/or the home media environment (e.g., parents' own media use, the presence of a media device the bedroom), resulting in a final sample of 103 studies.

\section{Coding procedures}

We extracted data from eligible studies using quantitative content analysis, which is the systematic assessment of content using categorical rules, and use of statistical methods to describe patterns in the content analyzed [17]. This method has been used in other studies of academic literature [18-20]. We developed a comprehensive codebook to standardize all coding procedures, and the 103 eligible studies were reviewed and coded by two trained coders.

Study characteristics coded include year of publication, geographic region, target child age, and study methodology type (e.g. quantitative, longitudinal). Parent/ 


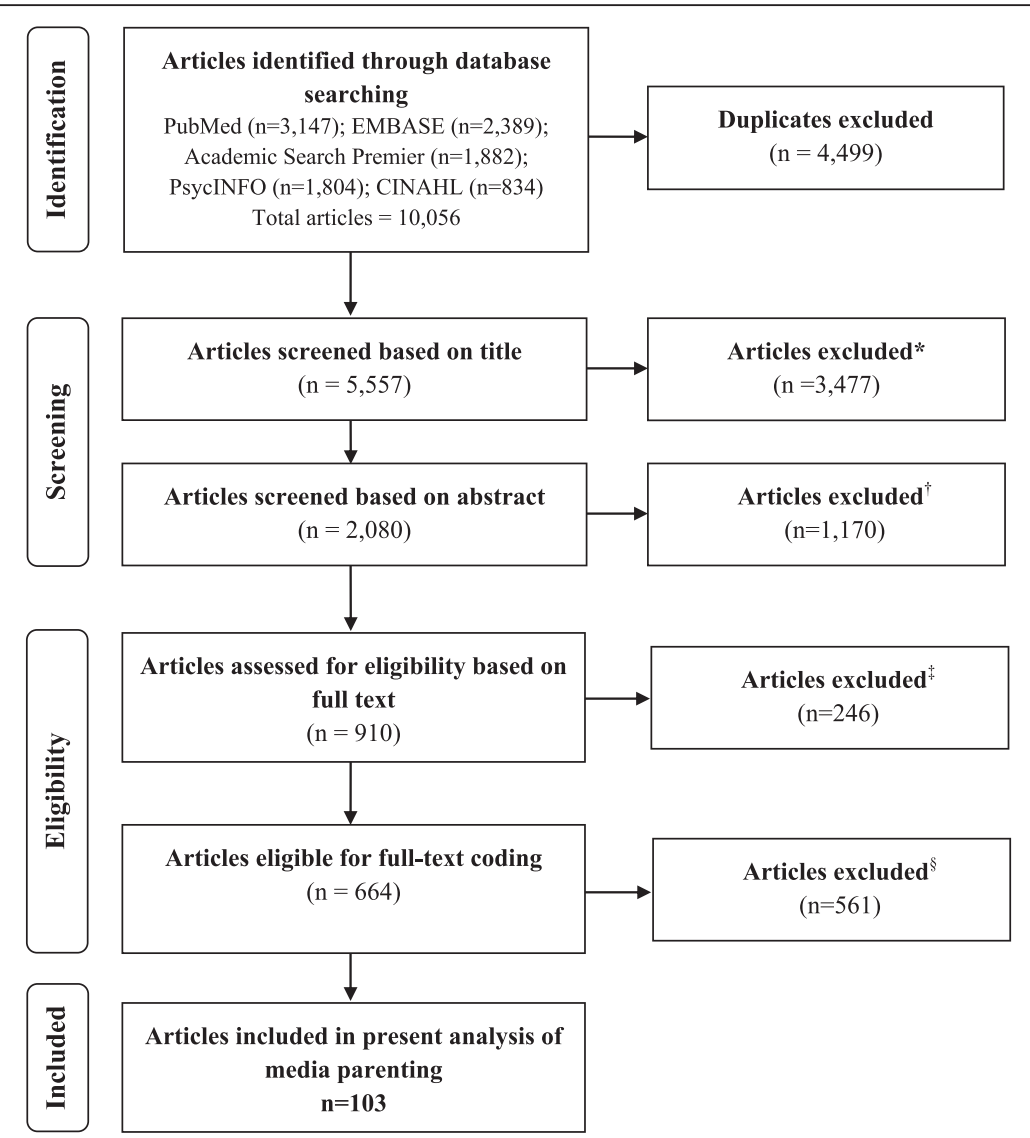

Fig. 1 PRISMA flowchart: summary of process to identify and screen eligible articles on media parenting and childhood obesity published between 2009 and 2015. Footnote: *Exclusion criteria: unrelated topic; children not focus of the study; not written in English; animal study; focuses on specific medical population; duplicate; manually deleted duplicates; ${ }^{\dagger}$ Exclusion criteria: unrelated topic $(n=210)$; intervention $(n=430)$; no parent research participants $(n=218)$; not focused on parenting $(n=261)$; not relevant to childhood obesity $(n=45)$; duplicate $(n=6)$; ${ }^{\ddagger}$ Exclusion criteria: missing PDF, duplicate, dissertation, retraction, or conference abstract $(n=49)$; not research $(n=9)$; not written in English $(n=4)$; parents not research participants ( $n=43)$; intervention study $(n=29)$; not focused on parenting $(n=58)$; not relevant to childhood obesity $(n=21)$; articles from the same study sample $(n=33) ;{ }^{\S}$ Exclusion criteria: no measure of media parenting and/or the home media environment

caregiver participant categories include sex, underserved groups (e.g. low-income/socioeconomic status [SES]), and ethnic/racial categories. Child and/or parent media use were coded if measured. Where media use was measured, the following were subsequently coded: data collection tool (e.g., questionnaire, $\log$ /journal); respondent reporting media use (child/parent); devices measured (e.g., TV, computer, smartphone); and other modes of child media exposure (e.g., media in the child's bedroom, screen use during mealtime). For media parenting, media-related parenting practices (e.g., media rules, parent-child coviewing, parent use of screen time for behavioral management) were coded, along with parent skills related to media use (e.g. media literacy, self-efficacy to control screen use). Finally, using the Family Ecological Model [21], we created categories for measures of the family ecology and social/emotional context factors including individual (e.g. child attributes), familial (e.g. parent cognitions), and community-level (e.g. neighborhood) factors.
The Family Ecological Model conceptualizes the complex and nuanced environments within which families operate [21], and provides a comprehensive framework available for examining the environmental factors associated with parenting around child obesogenic behaviors.

\section{Inter-coder reliability and analysis}

We assessed inter-coder reliability using both simple percent agreement and the Krippendorff's alpha (kalpha; $\alpha$ ) coefficient [22] for each coding category by double-coding a randomly selected sample of eligible studies $(15 \% ; n=15)$. We calculated reliability statistics across all 15 studies using STATA 13, resulting in an average k-alpha of 0.83 (range: $0.6-1.0$ ), and average simple percent agreement of 0.95 (range 0.8-1.0). All variables fell into an acceptable range of reliability. Twelve variables remained in our analysis although the $\mathrm{k}$-alpha statistic was 0.0 because the simple agreement was $90 \% ; \alpha=0$ indicates a lack of variability in the 
ratings of each variable, which occurred because those variables were rarely identified. We based our decisions for variable inclusion and cutoff points on previously documented recommendations [22-24].

Variable frequencies were calculated by variable using SAS 9.4 (Cary, NC), and each table presents the number of studies that include the specified characteristic, and the percentage of all eligible studies.

\section{Results}

Of the 103 eligible studies identified, media parenting $(n=36)$, the home media environment $(n=22)$, or both $(n=45)$ were measured (see Table 1). Studies were spread fairly evenly across the years of publication, although fewer studies were identified in 2009 . Over half of studies originated in the United States (U.S.) (53\%) and a little over a quarter from Europe/ United Kingdom (27\%). Target children were mostly preschool (38\%), elementary school (52\%), and middle school (43\%) ages; infants/toddlers were included in only $5 \%$ of studies and high school aged children in $13 \%$ of studies. Studies predominantly utilized quantitative methods (97\%) and adopted a cross sectional design (89\%). Although most studies included both male and female parent/caregiver participants (55\%), sample size distribution between males and females was quite uneven. Eighty eight percent of studies that included both male and female participants had female sample sizes that were $n=101$ or more (versus $35 \%$ of male samples), but $58 \%$ of male participant sample sizes were $n=100$ or less (versus $12 \%$ of female samples). A quarter of studies did not specify the sex of the participating parents. Although over a third of studies targeted racial/ethnic minority parents during recruitment, only $18 \%$ of studies included Asian parents/caregivers and $11 \%$ included Indigenous parents - these numbers remained constant for U.S.-based studies as well. Fewer than one in five studies targeted parents from low-SES backgrounds, and less than one in ten targeted immigrant parents.

A total of 81 studies - $79 \%$ of our sample - measured media use (see Table 2). Studies reported media use of children (36\%), parents (7\%), or both (36\%), and reporting of use corresponded with child age; media use was reported by parents for the vast majority of studies with children ages 0-5 (97\%), while both parent- and child-reported measures were used for the majority of studies with children ages 14-17 (75\%). Studies relying on child-only reporting were limited to children ages $6-17$. The vast majority of studies measured media use using questionnaires $(98 \%)$. Less than half of studies (43\%) provided information on the specific devices used; the remaining studies collapsed such information across multiple devices, making it impossible to parse the results for each device. For example, while TV was included in all studies measuring device use, it was measured distinctly from all other devices in only $43 \%$ of the studies. One in five studies reported the use of video games or computers separate from other devices, and report of use specific to smartphones or laptops was rare (1-3\% of studies). No studies measured tablet use. Over a third of studies measured the presence of media in the child's bedroom, most often the presence of a TV (34\%); however, as was the case for media use, measurement of the presence of newer technologies - laptops, tablets, or smartphones - in a child's bedroom was rare (5\%). Less frequently measured modes of child media exposure include screen use during mealtime $(17 \%)$, the number of devices in the home (17\%), and passive media exposure (e.g. finding the TV turned on when arriving home from school) (4\%). Measures of media use were also limited to the home environment; only one study measured media use outside the home, in this case in a child care setting.

Media parenting practices were assessed in $82 \%$ of studies (see Table 3). The most common media parenting construct measured in studies related to rules around media use (57 \%), and the majority of those studies focused on time limits. The study of rules specific to media use during meals (4\%), media in children's bedrooms $(3 \%)$, media use at specific times of the day (3\%), media use in relation to other activities (6\%), and on media use weekdays versus weekend days $(1 \%)$ was much less common. Following media rules, parent modeling of screen use, including parent-child co-viewing, was the next most commonly measured media parenting construct (42\%). Far fewer studies measured parents' use of screen time for behavior management (11\%), or parent encouragement of screen use (2\%). Measurement of parenting skills around media use was also low; parental beliefs, attitudes, and intentions were measured in $14 \%$ of studies and parents' media-specific selfefficacy in only $16 \%$. Results showed that $94 \%$ of studies did not include any measure of parent media literacy.

Forty three studies (42\%) measured a single ecological factor; $17 \%$ measured multiple factors. Family-level factors include parent cognitions (i.e. knowledge, beliefs, attitudes, intentions) and intrafamilial dynamics and were measured in about a third of studies (29 and $35 \%$ ); however, contextual factors at other levels were not often measured. Since child media use, exposure, and parenting is centered at home, we wanted to explore measurement of additional elements within the intrafamilial domain which could affect parenting practices and skills [25], such as parents' ability to set rules around screen time. Four percent or less of studies measured any of these factors, including parental self-efficacy (4\%), mental health (4\%), social support $(2 \%)$, parent stress $(2 \%)$, social norms 
Table 1 Study and parent/caregiver characteristics ( $N=103)$

\begin{tabular}{|c|c|c|}
\hline Study characteristic & Number & Percent \\
\hline \multicolumn{3}{|l|}{ Year } \\
\hline 2009 & 5 & $5 \%$ \\
\hline 2010 & 13 & $13 \%$ \\
\hline 2011 & 17 & $16 \%$ \\
\hline 2012 & 14 & $14 \%$ \\
\hline 2013 & 15 & $15 \%$ \\
\hline 2014 & 23 & $22 \%$ \\
\hline 2015 & 16 & $15 \%$ \\
\hline \multicolumn{3}{|l|}{ Geographic region } \\
\hline United States & 55 & $53 \%$ \\
\hline Europe/United Kingdom & 28 & $27 \%$ \\
\hline Australia/New Zealand/Papua New Guinea & 10 & $10 \%$ \\
\hline Asia & 6 & $6 \%$ \\
\hline Canada & 3 & $3 \%$ \\
\hline Mexico/Central America & 1 & $1 \%$ \\
\hline \multicolumn{3}{|l|}{ Age ranges $^{a}$} \\
\hline $0-1$ years (infant/toddler) & 5 & $5 \%$ \\
\hline $2-5$ years (preschool) & 39 & $38 \%$ \\
\hline 6-10 years (elementary school) & 54 & $52 \%$ \\
\hline 11-13 years (middle school) & 44 & $43 \%$ \\
\hline 14-18 years (high school) & 13 & $13 \%$ \\
\hline \multicolumn{3}{|l|}{ Study Methodology ${ }^{a}$} \\
\hline $\begin{array}{l}\text { Quantitative methods (vs. qualitative or } \\
\text { mixed methods) }\end{array}$ & 100 & $97 \%$ \\
\hline Longitudinal (vs. cross sectional) & 11 & $11 \%$ \\
\hline Parent/Caregiver Characteristics & N & $\%$ \\
\hline \multicolumn{3}{|l|}{ Sex of parent participants } \\
\hline Both males and females & 57 & $55 \%$ \\
\hline Females only & 20 & $19 \%$ \\
\hline Males only & 0 & $0 \%$ \\
\hline Not specified & 26 & $25 \%$ \\
\hline \multicolumn{3}{|l|}{ Underserved groups targeted in recruitment ${ }^{a}$} \\
\hline Racial/ethnic minority parents & 36 & $35 \%$ \\
\hline Low income/education/socioeconomic parents & 19 & $18 \%$ \\
\hline Immigrant parents & 9 & $9 \%$ \\
\hline \multicolumn{3}{|l|}{ Ethnic/Racial groups included ${ }^{a}$} \\
\hline White, Non-Hispanic & 44 & $43 \%$ \\
\hline Black/African American & 37 & $36 \%$ \\
\hline Hispanic & 35 & $34 \%$ \\
\hline Asian & 19 & $18 \%$ \\
\hline Indigenous & 11 & $11 \%$ \\
\hline Media-specific Measurements $^{a}$ & N & $\%$ \\
\hline Media parenting & 84 & $82 \%$ \\
\hline Media use & 81 & $79 \%$ \\
\hline
\end{tabular}

Table 1 Study and parent/caregiver characteristics ( $N=103)$ (Continued)

Home media environment $67 \quad 65 \%$
More than one answer could be selected, therefore totals may not equal
$00 \%$; 'bncome or education; includes recipients of income-eligible Federal
ssistance programs
$1 \%)$, parental control (1\%), food insecurity (1\%), accul-
uration (1\%), and child care challenges ( $1 \%)$. No studies
measures housing instability, family conflict, or parent
self-esteem.

\section{Discussion}

Given the ever-increasing ubiquity of media and screens in children's lives $[5,17]$ and the documented relationship between screen use and childhood obesity [26-28], the paucity of studies measuring media use and media parenting within the literature of parenting and childhood obesity is concerning. Results from this analysis can provide explicit guidance on future work needed in this area.

The vast majority of studies on media parenting originated from the United States, Europe/United Kingdom, and Australia. Although child obesity rates are increasing in low/middle income regions [29], there is a lack of representation of those areas in our sample, with only $7 \%$ of studies originating from Asia and Mexico/Central America, and no studies from Africa or South America. While it is possible that there are still disparate levels of screen use in low/middle versus high-income countries, which would temper the association between screen behaviors and childhood obesity, we cannot know this without measurement.

Our analysis examined parent populations targeted for participation, and found more than half of studies included both female and male parent participants, which presents an opportunity to engage both mothers and fathers around media parenting as part of efforts to reduce child obesity. However, greater work is clearly needed in this area, as we found that sample size distributions between male and female participants were skewed to include many more mothers/female caregivers than fathers/male caregivers. These disparities are addressed in a forthcoming manuscript. Our study also revealed other shortcomings in specific parent group inclusion. Although parenting around obesogenic behaviors remains important in adolescence [28, 30], parents of teenagers were also largely absent from the studies we reviewed.

While $35 \%$ studies included minority parents, the lack of inclusion of Asian and Indigenous parents, particularly in U.S.-based studies, is concerning given that Asians are the fastest growing minority group in the U.S., followed by Native Hawaiian/Pacific Islanders [31]. 
Table 2 Measures of media use $(N=103)$

\begin{tabular}{|c|c|c|}
\hline Characteristic & Number & Percen \\
\hline \multicolumn{3}{|l|}{ Media use measured } \\
\hline No & 22 & $21 \%$ \\
\hline$Y_{e s}^{a}$ & 81 & $79 \%$ \\
\hline Child use only & 37 & $36 \%$ \\
\hline Parent use only & 7 & $7 \%$ \\
\hline Both parent and child use & 37 & $36 \%$ \\
\hline \multicolumn{3}{|l|}{ Method used to measure media use } \\
\hline Questionnaire & 79 & $77 \%$ \\
\hline Log/journal & 1 & $1 \%$ \\
\hline Video diary & 0 & $0 \%$ \\
\hline Other & 1 & $1 \%$ \\
\hline \multicolumn{3}{|l|}{ Respondent reporting media use } \\
\hline Parent reported & 55 & $53 \%$ \\
\hline Child reported & 5 & $5 \%$ \\
\hline Both parent and child reported & 20 & $19 \%$ \\
\hline \multicolumn{3}{|l|}{ Devices Measured ${ }^{a}$} \\
\hline Device-specific data are available & 44 & $43 \%$ \\
\hline TV & 44 & $43 \%$ \\
\hline Video games & 21 & $20 \%$ \\
\hline Computer & 21 & $20 \%$ \\
\hline DVD/video player & 12 & $12 \%$ \\
\hline Smartphone & 3 & $3 \%$ \\
\hline Laptop & 1 & $1 \%$ \\
\hline Tablet & 0 & $0 \%$ \\
\hline Device-specific data are not available & 37 & $36 \%$ \\
\hline \multicolumn{3}{|l|}{ Other measures of child media exposure ${ }^{a}$} \\
\hline Media in the child's bedroom & 38 & $37 \%$ \\
\hline TV & 35 & $34 \%$ \\
\hline Computer & 16 & $16 \%$ \\
\hline Video games & 11 & $11 \%$ \\
\hline DVD/video player & 7 & $7 \%$ \\
\hline Laptop & 3 & $3 \%$ \\
\hline Tablet & 1 & $1 \%$ \\
\hline Smartphone & 1 & $1 \%$ \\
\hline Screen use during mealtime & 18 & $17 \%$ \\
\hline Number of devices in home & 17 & $17 \%$ \\
\hline Passive media exposure & 4 & $4 \%$ \\
\hline
\end{tabular}

${ }^{\mathrm{a} M o r e}$ than one answer could be selected, therefore totals may not equal $100 \%$; ${ }^{b}$ Multiple devices were measured in a single question (e.g., time per day watching TV/playing video games) resulting in no device-specific information

It has been suggested that parent attitudes and beliefs about media use vary by culture [32], and that youth media use varies by race/ethnicity [33-36], so it is important to include parents across multiple racial/ethnic groups to document those nuances. It is concerning that
Table 3 Media parenting and family context constructs measured in eligible studies $(N=103)$

\begin{tabular}{|c|c|c|}
\hline Characteristic & Number & Percent \\
\hline \multicolumn{3}{|l|}{ Parenting Practices } \\
\hline Media rules ${ }^{a}$ & 59 & $57 \%$ \\
\hline Time limits & 46 & $45 \%$ \\
\hline Screen use in relation to other activities & 6 & $6 \%$ \\
\hline Screen use during meals & 4 & $4 \%$ \\
\hline Time of day screens can be used & 3 & $3 \%$ \\
\hline Media use in child's bedroom & 3 & $3 \%$ \\
\hline Weekday vs. weekend screen use & 1 & $1 \%$ \\
\hline Other & 17 & $17 \%$ \\
\hline $\begin{array}{l}\text { Parent modeling of screen use (including } \\
\text { parent-child co-viewing) }\end{array}$ & 43 & $42 \%$ \\
\hline $\begin{array}{l}\text { Parent use of screen time for behavior } \\
\text { management }\end{array}$ & 11 & $11 \%$ \\
\hline Parent encouragement of screen use & 2 & $2 \%$ \\
\hline \multicolumn{3}{|l|}{ Parenting Skills } \\
\hline $\begin{array}{l}\text { Parent beliefs/attitudes/intentions about } \\
\text { media use }\end{array}$ & 14 & $14 \%$ \\
\hline Parental self-efficacy related to child screen use & 16 & $16 \%$ \\
\hline Parent media literacy & 6 & $6 \%$ \\
\hline Ecological context factors ${ }^{a}$ & 62 & $60 \%$ \\
\hline Intrafamilial dynamics & 36 & $35 \%$ \\
\hline Parent cognitions & 30 & $29 \%$ \\
\hline Neighborhood/community & 13 & $13 \%$ \\
\hline Child attributes & 6 & $6 \%$ \\
\hline
\end{tabular}

${ }^{a}$ More than one answer could be selected, therefore totals may not equal $100 \%$

a limited number of studies recruited low income/SES parents, given the pervasiveness of childhood obesity and the fact that barriers experienced by parents in these groups have been documented $[37,38]$. Specific recommendations for recruiting under-resourced groups have been previously noted [39, 40]; we would add that our analysis highlights the continued need for protocols that specifically target low-income parents in order to document persisting disparities, identify the circumstances within which people are parenting, and to strengthen strategies to target underserved populations.

Our analysis shows that measures of child media use in studies focused on childhood obesity are largely centered on television viewing, which does not reflect the varied modes of exposure children experience. This could potentially be explained by low popularity of “newer' devices (e.g. tablets) among children, particularly in the earlier publication years included in our analysis. However, reports about the changing landscape of child device use [41], and rapid increases in such use [42] indicate that child use of these devices was already 
underway in the earlier years of our search parameters. Additionally, while several studies measured the presence of such devices in children's bedrooms (i.e. laptops, smartphones, and tablets), only one study measured use of laptops, and no studies measured parent or child use of tablets. We encourage researchers to focus on capturing the full landscape of media devices used by children in future research. Many studies measuring media use utilize questions that collapse device categorization (e.g. defining computers as "desktops/laptops/tablets"), creating unspecified results which obscures device-specific media use by children. As some devices lend themselves to potentially increasing child exposure (e.g. portable devices such as handheld gaming devices versus stationary devices such as TVs), accurately documenting child media exposure by device-type is crucial to understanding their exposure across time and settings, as well as how parents are or are not setting bounds to that exposure.

Relatedly, our analysis shows that although data on media parenting is being collected, measures generally focus on the existence of rules regarding time limits and do not account for settings outside of the home, where children could be using media, such as in the car on the way to school or during afterschool programs. Additionally, greater consideration should be given to measuring the ways media is used as a mode of parenting, such as the use of media for managing child behavior, incidence of media viewing as a family activity, or screen use during meals. More work is needed in order to better understand the ways in which children are using media and how parents are allowing or responding to that use.

Another surprising omission from this literature is measurement of parent media literacy, or other relevant skills such as digital literacy. Measures of media literacy in the literature typically focus on assessments among children or parent acquisition of media literacy skills $[43,44]$. Consistent definitions and validated measures of this are currently lacking, but are needed in order to understand and quantify existing parent knowledge about media. Parents cannot provide proper supervision of media they are not familiar with.

Observational studies on parenting and childhood obesity, particularly as precursors to intervention efforts, are meant to have a thorough understanding of parent experience, which should include accounting for the contexts within which parenting occurs. Family ecology and social and emotional contexts shape and drive families' day-today experiences and behaviors. Our analysis shows that more attention could be paid to neighborhood/community factors, including social capital, neighborhood safety, and deprivation. Child-specific factors, such as temperament and self-regulation were also absent from the literature. Just as with family-specific factors, these domains may also impact parenting practices around media use, and their measurement can inform behavior change strategies or associations with risk of child overweight.

This analysis is not without limitations. We restricted our review to English-language and non-intervention studies, which may have limited our final sample of studies available for analysis. We refined our initial search terms to collect studies that included parents as research participants and those with a focus on parenting related to childhood obesity (i.e. parenting practices related to diet, physical activity, and sedentary behaviors). In so doing, we will not have captured studies that explore parenting solely related to media content, and may have missed, for example, studies that measure parent regulation of television food advertisements and commercials. By placing these limits on our search terms, we avoided having many irrelevant studies in our initial sample of studies, and we are confident that our sample accurately reflects the literature on parenting of media specifically as it relates to childhood obesity. An area of future research could be an analysis of measurements of the content or platforms of media used by children, such as active gaming or social media. We did not assess risk of bias across studies or strength of evidence for study outcomes because these were not relevant to our research aims. There are also many strengths of this analysis. The studies reviewed were drawn from a broad range of publication disciplines, included both U.S.based and non-U.S. studies, broadly examined media parenting in the context of childhood obesity, and examined the presence of environmental factors that may impact screen viewing and parenting practices thereof.

\section{Conclusions}

More detailed measurements of media use that reflects current technology trends and diverse contexts of use are needed to better understand media use and parent regulation of child media exposure. Future observational studies should consider recruitment protocols which target more diverse samples of parents, and consider including measures of the ecological context within which families live to more fully understand factors that may impact media parenting and, subsequently, child risk for overweight.

\section{Ethics approval and consent to participate \\ Not applicable.}

\section{Consent for publication \\ Not applicable.}

\section{Availability of data and materials}

The dataset supporting the conclusions of this article are available upon request to the corresponding author. 


\section{Additional files}

Additional file 1: Search Terms (PubMed). (DOCX 14 kb)

\section{Abbreviations}

SES: socioeconomic status; TV: television; U.S.: United States.

\section{Competing interests}

The authors declare that they have no competing interests.

\section{Authors' contributions}

AA conceptualized and designed the study, led the data analysis, and drafted the first version of the manuscript; $A A, K D$, and $J M$ designed the coding scheme and data collection instrument; $A A, C G, S G, C S, K D$, and JM made substantial contributions to data acquisition; SN made substantial contributions to the data analyses. All authors performed critical reviews for intellectual content and approved the final manuscript as submitted.

\section{Funding}

Study authors were supported with funding from a number of pre-doctoral training grants including the Initiative to Maximize Student Diversity from the National Institute of General Medical Sciences of the National Institutes of Health (\# GM055353-13; CS), a training award from the Maternal and Child Health Bureau (\#T76MC00001; CS) and the Perinatal and Pediatric Epidemiology pre-doctoral training grant from the National Institute of Child Health and Human Development (T32HD060454; SN).

\section{Author details}

${ }^{1}$ Department of Nutrition, Harvard T.H. Chan School of Public Health, 665 Huntington Avenue, Boston, MA 02121, USA. ²Department of Epidemiology, Harvard T.H. Chan School of Public Health, Boston, Massachusetts, USA ${ }^{3}$ Department of Social and Behavioral Sciences, Harvard T.H. Chan School of Public Health, Boston, Massachusetts, USA. ${ }^{4}$ Department of Health Policy, Management and Behavior, University at Albany, SUNY, Albany, New York, USA

\section{Received: 24 November 2015 Accepted: 23 March 2016}

\section{Published online: 14 April 2016}

\section{References}

1. American Academy of Pediatrics. Children, adolescents, and the media. Pediatrics. 2013;132:959-61.

2. Strasburger VC, Jordan AB, Donnerstein E. Health effects of media on children and adolescents. Pediatrics. 2010;125:756-67.

3. O'Connor TM, Hingle M, Chuang RJ, Gorely T, Hinkley T, Jago R, et al. Conceptual understanding of screen media parenting: report of a working group. Child Obes. 2013:9(Suppl):S110-8.

4. Comstock G, Scharrer E. The use of television and other screen media. In: Singer DG, Singer $J$, editors. Handbook of children and the media. London: Sage; 2012. p. 13-44

5. Rideout VJ, Foehr UG, Roberts DF. Generation M2: Media in the Lives of 8 to 18-year olds. 2010. http://kff.org/other/report/generation-m2-media-inthe-lives-of-8-to-18-year-olds/. Accessed 3 Nov 2015.

6. Steele RM, van Sluijs EM, Cassidy A, Griffin SJ, Ekelund U. Targeting sedentary time or moderate- and vigorous-intensity activity: independent relations with adiposity in a population-based sample of 10-y-old British children. Am J Clin Nutr. 2009;90:1185-92.

7. Jordan AB, Kramer-Golinkoff EK, Strasburger VC. Does adolescent media use cause obesity and eating disorders? Adolesc Med State Art Rev. 2008;19: 431-49. viii-ix

8. Strasburger VC. Children, adolescents, obesity, and the media. Pediatrics 2011;128:201-8.

9. Radesky JS, Schumacher J, Zuckerman B. Mobile and interactive media use by young children: the good, the bad, and the unknown. Pediatrics. 2015 135:1-3.

10. Lloyd AB, Lubans DR, Plotnikoff RC, Collins CE, Morgan PJ. Maternal and paternal parenting practices and their influence on children's adiposity, screen-time, diet and physical activity. Appetite. 2014;79:149-57.
11. Palfreyman Z, Haycraft E, Meyer C. Parental modelling of eating behaviours: observational validation of the Parental Modelling of Eating Behaviours scale (PARM). Appetite. 2015;86:31-7.

12. Daniel E, Madigan S, Jenkins J. Paternal and Maternal Warmth and the Development of Prosociality Among Preschoolers. J Fam Psychol. 2015; [Epub ahead of print].

13. Jago R, Edwards MJ, Urbanski CR, Sebire SJ. General and specific approaches to media parenting: a systematic review of current measures, associations with screen-viewing, and measurement implications. Child Obes. 2013; 9(Suppl):S51-72.

14. Jago R, Wood L, Zahra J, Thompson JL, Sebire SJ. Parental control, nurturance, self-efficacy, and screen viewing among 5- to 6-year-old children: a cross-sectional mediation analysis to inform potential behavior change strategies. Child Obes. 2015;11:139-47.

15. Higgins J, S. G. Cochrane Handbook for Systematic Reviews of Interventions. 2011. http://www.cochrane-handbook.org. Accessed 11 Mar 2016

16. Gicevic S, Aftosmes-Tobio A, Manganello J, Ganter C, Simon CL, Newlan S, Davison KK. Parenting and childhood obesity research: a quantitative content analysis of published research 2009-2015. Obesity Reviews. 2016 [In press].

17. Rich M. Moving from child advocacy to evidence-based care for digital natives. JAMA Pediatr. 2014;168:404-6.

18. Manganello J, Blake N. A study of quantitative content analysis of health messages in U.S. media from 1985 to 2005. Health Commun. 2010;25:387-96.

19. Hussain H, Omer SB, Manganello JA, Kromm EE, Carter TC, Kan L, Stokley S, Halsey NA, Salmon DA. Immunization safety in US print media, 1995-2005. Pediatrics. 2011;127 Suppl 1:S100-6.

20. Smith KC, Girasek DC, Baker SP, Manganello JA, Bowman SM, Samuels A, Gielen AC. 'It was a freak accident': an analysis of the labelling of injury events in the US press. Inj Prev. 2012;18:38-43.

21. Davison KK, Jurkowski JM, Lawson HA. Reframing family-centred obesity prevention using the Family Ecological Model. Public Health Nutr. 2013;16: 1861-9.

22. Hayes A, Krippendorff K. Answering the call for a standard reliability measure for coding data. Commun Meth Meas. 2007:1:77-89.

23. Krippendorff K. Agreement and information in the reliability of coding Commun Meth Meas. 2011:5:93-112.

24. Krippendorff K. Content analysis: An introduction to its methodology. 2nd ed. Thousand Oaks: Sage; 2004

25. Lampard AM, Jurkowski JM, Davison KK. Social-cognitive predictors of lowincome parents' restriction of screen time among preschool-aged children. Health Educ Beh. 2013;40:526-30.

26. Falbe J, Davison KK, Franckle RL, Ganter C, Gortmaker SL, Smith L, Land T, Taveras EM. Sleep duration, restfulness, and screens in the sleep environment. Pediatrics. 2015;135:e367-75.

27. Falbe J, Rosner B, Willett WC, Sonneville KR, Hu FB, Field AE. Adiposity and different types of screen time. Pediatrics. 2013;132:e1497-505.

28. Falbe J, Willett WC, Rosner B, Gortmaker SL, Sonneville KR, Field AE. Longitudinal relations of television, electronic games, and digital versatile discs with changes in diet in adolescents. Am J Clin Nutr. 2014;100:1173-81.

29. Popkin BM, Doak CM. The obesity epidemic is a worldwide phenomenon. Nutr Rev. 1998:56:106-14.

30. Nicholls L, Lewis AJ, Petersen S, Swinburn B, Moodie M, Millar L. Parental encouragement of healthy behaviors: adolescent weight status and healthrelated quality of life. BMC Public Health. 2014;14:369.

31. U.S. Census Bureau. American Community Survey Demographic and Housing Estimates 2010-2013. http://factfinder.census.gov/faces/ tableservices/jsf/pages/productview.xhtml?pid=ACS_13_5YR_DP05\&src=pt. Accessed 26 Aug 2015

32. Njoroge WF, Elenbaas LM, Garrison MM, Myaing M, Christakis DA. Parental cultural attitudes and beliefs regarding young children and television. JAMA Pediatr. 2013;167:739-45.

33. Rideout VJ. Zero to Eight: Children's Media Use in America 2013. 2013. http://www.commonsensemedia.org/research/zero-to-eight-childrensmedia-use-in-america-2013. Accessed 3 Nov 2015.

34. Herrick KA, Fakhouri TH, Carlson SA, Fulton JE. TV watching and computer use in U.S. youth aged 12-15, 2012. NCHS Data Brief. 2014;157:1-8.

35. Carson V, Staiano AE, Katzmarzyk PT. Physical activity, screen time, and sitting among U.S. adolescents. Pediatr Exerc Sci. 2015:27:151-9.

36. Fulton JE, Wang X, Yore MM, Carlson SA, Galuska DA, Caspersen CJ. Television viewing, computer use, and BMI among U.S. children and adolescents. J Phys Act Health. 2009;6 Suppl 1:S28-35. 
37. Wang Y, Beydoun MA. The obesity epidemic in the United States-gender, age, socioeconomic, racial/ethnic, and geographic characteristics: a systematic review and meta-regression analysis. Epidemiol Rev. 2007;29:6-28.

38. Freedman DS, Khan LK, Serdula MK, Ogden CL, Dietz WH. Racial and ethnic differences in secular trends for childhood BMI, weight, and height. Obesity. 2006;14:301-8.

39. Hinojosa MS, Kadivar H, Fernandez-Baca D, Chisholm T, Thompson LA Stanford J, Shenkman E. Recruiting low income and racially/ethnically diverse adolescents for focus groups. Matern Child Health J. 2014;18:1912-8.

40. Bonevski B, Randell M, Paul C, Chapman K, Twyman L, Bryant J, et al. Reaching the hard-to-reach: a systematic review of strategies for improving health and medical research with socially disadvantaged groups. BMC Med Res Methodol. 2014;14:42.

41. Kaiser Family Foundation. Generation M2: Media in the Lives of 8- to 18year olds. 2010. http://kff.org/other/report/generation-m2-media-in-the-livesof-8-to-18-year-olds/. Accessed 3 Nov 2015.

42. Common Sense Media. Zero to Eight: Children's Media Use in America 2013. 2013. http://www.commonsensemedia.org/research/zero-to-eightchildrens-media-use-in-america-2013. Accessed 3 Nov 2015.

43. Primack BA, Gold MA, Land SR, Fine MJ. Association of cigarette smoking and media literacy about smoking among adolescents. J Adolesc Health. 2006:39:465-72.

44. Bergsma LJ, Carney ME. Effectiveness of health-promoting media literacy education: a systematic review. Health Educ Res. 2008:23:522-42.

\section{Submit your next manuscript to BioMed Central and we will help you at every step:}

- We accept pre-submission inquiries

- Our selector tool helps you to find the most relevant journal

- We provide round the clock customer support

- Convenient online submission

- Thorough peer review

- Inclusion in PubMed and all major indexing services

- Maximum visibility for your research

Submit your manuscript at www.biomedcentral.com/submit

) Biomed Central 